\title{
WNT7A (rs104893832) polymorphism increases the risk of recurrent spontaneous abortion in Iranian women
}

\author{
Manouchehr Mazdapour*, Mahmood Dehghani Ashkezari*, \\ and Seyed Morteza Seifati*
}

\begin{abstract}
\section{BACKGROUND}

Recurrent spontaneous abortion is defined as the occurrence of three or more clinical miscarriages in one woman. Several factors, including genetics and environmental factors, are involved in this kind of infertility, in which WNT7A (rs104893832) polymorphism plays a major role. The aim of the present study was to determine the association between a common polymorphism of WNT7A (rs104893832) with recurrent spontaneous abortion in females.
\end{abstract}

\section{METHODS}

In the present case-control study, the WNT7A(rs104893832) polymorphism was investigated in 70 women with recurrent spontaneous abortion as cases and 100 women with at least one child and no history of infertility or abortion as controls. Polymerase chain reaction- restriction fragment length polymorphism (PCR-RFLP) was used to investigate the WNT7A (rs104893832) polymorphism in both case and control groups. The data were subsequently analyzed using the chi-square and logistic regression tests by SPSS software (version 18.0).

\section{RESULTS}

A significant association was found between the WNT7A (rs104893832) polymorphism and recurrent spontaneous abortion $(\mathrm{OR}=25.00,95 \%$ $\mathrm{CI}=5.52-157.09 ; \mathrm{p}<0.0001)$. Our finding showed that $\mathrm{G}$ allele frequency in women with recurrent spontaneous abortion was significantly different compared to the control group. $(\mathrm{OR}=6.42,95 \% \mathrm{CI}=2.82-15.16$; $\mathrm{p}<0.0001)$. Therefore, genetic variation in WNT7A (rs104893832) polymorphism may play a role in recurrent spontaneous abortion.

\section{CONCLUSION}

This study revealed that WNT7A (rs 104893832) polymorphism increased the risk of recurrent spontaneous abortion. Knowledge of these mutations and polymorphisms can provide an insight into the prognosis for individual patients. Therefore, further studies are necessary to establish the association of WNT7A (rs104893832) polymorphism with recurrent spontaneous abortion in a larger population.

Keywords: Recurrent spontaneous abortion, WNT7A, polymorphism, infertility female
*Medical Biotechnology Research Center, Ashkezar Branch, Islamic Azad University, Ashkezar, Yazd, Iran

\section{Correspondence:}

Dr.Mahmood Dehghani Ashkezari Medical Biotechnology Research Center, Ashkezar Branch, Islamic Azad University, Ashkezar, Yazd, Iran Email: drmdehghani31@gmail.com ORCID ID : orcid.org/0000-00025349-2083

Date of first submission, June 28, 2018 Date of final revised submission, September 12, 2018

Date of acceptance, September 13, 2018

This open access article is distributed under a Creative Commons AttributionNon Commercial-Share Alike 4.0 International License

Cite this article as: Mazdapour M, Ashkezari MD, Seifati SM. WNT7A (rs104893832) polymorphism increases the risk of recurrent spontaneous abortion in Iranian women. Univ Med 2018;37:167-72. doi: 10.18051/ UnivMed.2018.v37.167-172 


\section{INTRODUCTION}

Recurrent spontaneous abortion (RSA) is associated with the recurring loss of pregnancy (three times or more) and causes many difficulties for couples. ${ }^{(1)}$ There are many factors involved in RSA, including anatomical factors (approximately 10-15\%), ${ }^{(2)}$ endocrine-related factors (approximately 17-20\%), ${ }^{(3)}$ infections (approximately $0.5 \%),{ }^{(4)}$ immunological factors (approximately 3-5\%), ${ }^{(5)}$ thrombotic factors (approximately 15\%), ${ }^{(6)}$ environmental factors (approximately 5-10\%), and unexplained etiologies (approximately 20-30\%). ${ }^{(7)}$ Genetic factors are one of the most important factors involved in RSA (approximately 2-4\%) and many different kinds of genes are involved in this process. Gene polymorphism is associated with infertility and plays a central role in RSA. ${ }^{(8)}$ In addition, parental chromosome rearrangement e.g. robertsonian translocations, chromosomal inversions, and insertions is one of the main causes of RSA. For human fertility several genes are required which are so conserved. Several infertility disorders are associated with these genes. Each gene has a different role in the process of fertility and any change in the sequence of these genes can lead to infertility. The most important genes in this regard are Hoxa10 (frequent embryo loss prior to implantation), ${ }^{(9)}$ Hoxa11 (uterine defects), ${ }^{(10)} \mathrm{Ptx} 3$ (ovulation defects), ${ }^{(11)}$ Nos3 (compromised ovulation, delayed meiotic progression from metaphase I), ${ }^{(12)}$ and WNT7A (abnormal development of oviducts and uterus). ${ }^{(13)}$ The WNT7A gene is located on chromosome 3 (p25.1 region). WNT7A is a member of the Wnt gene family and plays a role in ensuring successful pregnancy by controlling fertilization, implantation and progression. The gene is related to many other developmental processes such as cell fate specification, cell proliferation, cell migration and pregnancy. This gene encodes secreted signaling proteins, which in turn are associated with oncogenesis and developmental processes such as pregnancy. ${ }^{(14)}$ Therefore, the investigation of the WNT7A gene can throw new light on RSA. Notably, the available evidence indicates that the WNT7A gene has a critical role in the survival and maintenance of oocytes; thus with regard to its roles, these likely manifest in fertility. This research is the first to report that WNT7A (rs104893832) polymorphism has an intense effect on RSA; however, further studies are necessary to confirm the association in other populations. The aim of the present case-control study was to estimate allele and genotype frequencies of WNT7A (rs 104893832) polymorphism, in order to investigate the potential association between this polymorphism and spontaneous abortion in our population.

Therefore, the current study was planned to investigate the role of WNT7A (rs104893832) polymorphism in RSA in Iranian females.

\section{METHODS}

\section{Research design}

A case-control study was performed at Tehran Women's General Hospital (Mirza Kochak Khan), Tehran, Iran, between January 2015 and October 2016.

\section{Research subjects}

Seventy women with more than 2 miscarriages (18-35 years old) and 100 healthy women with a history of at least one live birth and no history of infertility or abortion as controls. In this study, for the sample size determination, we used an online sample size program, https:// www.stat.ubc.ca/ rollin/stats/ssize/by clicking of "Comparing Proportions for Two Independent Samples", proportion in the population to be sampled (both control and case). Based on related previous studies, $\mathrm{p} 1=0.7, \mathrm{p} 2=0.9, \alpha=0.05$, and power $=0.8$. The required sample size (for each sample separately) was 62 . The patients were also examined for known factors affecting RSA, including for anatomical abnormalities, immunological factors and endocrine factors and testosterone, factor V Leiden and prothrombin mutations, and were indicated to be normal with 
regard to such factors. All patients and their partners had a normal karyotype. The control group was healthy women with no history of abortion and at least one live birth.

\section{Genotyping of WNTA}

Genomic DNA from venous blood samples $(5 \mathrm{ml})$ was isolated using a DNA Extraction kit (GenID GmbH, Germany) according to the manufacturer's instructions. The purity and concentration of genomic DNA were evaluated using a NanoDrop spectrophotometer and a concentration of $50 \mathrm{ng} / \mu \mathrm{l}$ was prepared for the working tubes. Amplification was done using specific primers, $5^{\prime}$ - CCGACGCCATCATCGT CATA-3'as forward primer, and 5' GTAGCGGATGTCGGCAGAG - $3^{\prime}$ as reverse primer. The reactions were prepared in a tube containing $2 \mu \mathrm{L}$ of forward primer, $2 \mu \mathrm{L}$ of reverse primer, $5.5 \mu \mathrm{L}$ of sterilized distilled water, $3 \mu \mathrm{L}$ of DNA $(50 \mathrm{ng} / \mathrm{ml})$, and $12.5 \mu \mathrm{L}$ of Master Mix. The PCR cycling conditions were maintained with an initial denaturation step for $5 \mathrm{~min}$ at $94^{\circ} \mathrm{C}$, followed by 35 cycles of $45 \mathrm{sec}$ at $94{ }^{\circ} \mathrm{C}, 40 \mathrm{sec}$ at $59^{\circ} \mathrm{C}$ and $45 \mathrm{sec}$ at $72^{\circ} \mathrm{C}$ and the final extension step at $72^{\circ} \mathrm{C}$ for $5 \mathrm{~min}$. The WNT7A (rs104893832) polymorphism was determined on the basis of product size-band using BsrDI restriction enzyme digestion. The amplified fragment after digestion with BsrDI restriction enzyme, created two fragments (145 $\mathrm{bp}$ and $163 \mathrm{bp}$ ) that indicated the presence of $\mathrm{G} / \mathrm{G}$ genotype, and the appearance of one undigested $308 \mathrm{bp}$ fragment indicated the presence of A/A genotype, while the presence of three fragments (308bp, 145bp and 163bp) indicated A/G genotype (Figure1). The PCR products were separated by electrophoresis on $3 \%$ agarose gel. In addition, 50bp DNA marker was used in this experiment and the gel was visualized on a gel documentation system using GelRed dye.

\section{Statistical analysis}

Statistical analysis was performed using SPSS software (version 18.0; SPSS Inc,
Chicago, IL, USA). The odds ratios (ORs) and 95\% confidence intervals (CIs) were determined using binary logistic regression, and the genotype and allele frequencies were compared using the $\chi^{2}$ test. A $\mathrm{p}<0.05$ was considered to indicate statistical significance.

\section{Ethical clearance}

The study has been approved by the Research Committee at the Islamic Azad University, Yazd (IR.IAU.YAZD.REC.1396, 15). All subjects were informed of the study protocol in written and verbal form and provided written informed consent.

\section{RESULTS}

The genotype and allele frequencies of WNT7A (rs104893832) polymorphism in women with RSA and normal controls are shown in Table I. The results demonstrated that the frequencies of AA, AG, AG genotypes were $92.8 \%, 2.9 \%$ and $4.3 \%$ respectively in cases and $52 \%, 40 \%$ and $8 \%$ in controls. The frequency of AG genotype was significantly different in cases and controls $(\mathrm{OR}=25.00,95 \% \mathrm{CI}=5.52-157.09 ; \mathrm{p}<0.0001)$. In addition, the frequencies of $\mathrm{A}$ and $\mathrm{G}$ alleles were $94.2 \%$ and $5.8 \%$ in cases, and $72 \%$ and $28 \%$ in controls and $\mathrm{G}$ allele was significantly different between the case and control groups ( $\mathrm{OR}=6.42$, $95 \% \mathrm{CI}=2.82-15.16 ; \mathrm{p}<0.0001)$. WNT7A (rs104893832) polymorphism significantly increased the risk of RSA in our research subjects. Therefore, WNT7A (rs104893832) polymorphism might be related to RSA in our research subjects.

\section{DISCUSSION}

This study was designed to determine the association between WNT7A (rs104893832) polymorphism and RSA. Our results indicate that there are significant relations between this polymorphism and RSA. This research is the first to report that the WNT7A (rs104893832) polymorphism has an intense effect on RSA; however, further studies are necessary to confirm 
Table 1. Genotype and allele frequencies of WNT7A (rs104893832) polymorphism in women with RSA and in controls

\begin{tabular}{ccccc}
\hline Genotype WNTA7A & Case (n, \%) & Control (n,\%) & OR (95\% C.I.) & p value \\
\hline AA & $65(92.8)$ & $52(52.0)$ & 1 (Reference) & - \\
AG & $2(2.9)$ & $40(40.0)$ & $25.00(5.52-157.09)$ & $<0.0001$ \\
GG & $3(4.3)$ & $8(8.0)$ & $3.33(0.75-16.00)$ & 0.086 \\
Allele & & & & \\
A & $132(94.2)$ & $144(72.0)$ & $6.42(2.82-15.16)$ & $<0.0001$ \\
G & $8(5.8)$ & $56(28.0)$ & & \\
\hline
\end{tabular}

The data was analyzed with binary logistic regression and chi-square test. $(\mathrm{p}<0.0001)$

the association in other populations. The literature review demonstrated that the majority of the studies assessed the role WNT7A in the pathogenesis of RSA. A study by Vainio et al. ${ }^{(15)}$ suggested that the Wnt family including Wnt4 and specially WNT7A gene is certainly involved in sexual developmental processes and maintenance of pregnancy. A study by Fan et al. ${ }^{(16)}$ showed that WNT7A expression plays a very important role in the human endometrium and in infertility. In another study, Tepekoy et al. ${ }^{(17)}$ reported that WNT7A plays a key role in pre-implantation and implantation and guides uterine development. van Amerongen et al. ${ }^{(18)}$ demonstrated that Wnt signaling plays a part in fertility. However there is a vast list of genes involved in infertility. Among them, WNT7A is one of the most essential genes that affect fertility. Mutations and polymorphisms in WNT7A gene can cause different kinds of infertility and biological functions of WNT7A are vital in the regulation of pregnancy. Our results demonstrated that there was an association between this polymorphism of WNT7A gene and RSA. Our finding in this research can be a sign of this fact that the polymorphism plays an important role in RSA. In addition, results obtained by Dunlap et al ${ }^{(19)}$ revealed that the deletion of the WNT7A gene inhibits uterine gland morphogenesis and causes infertility in

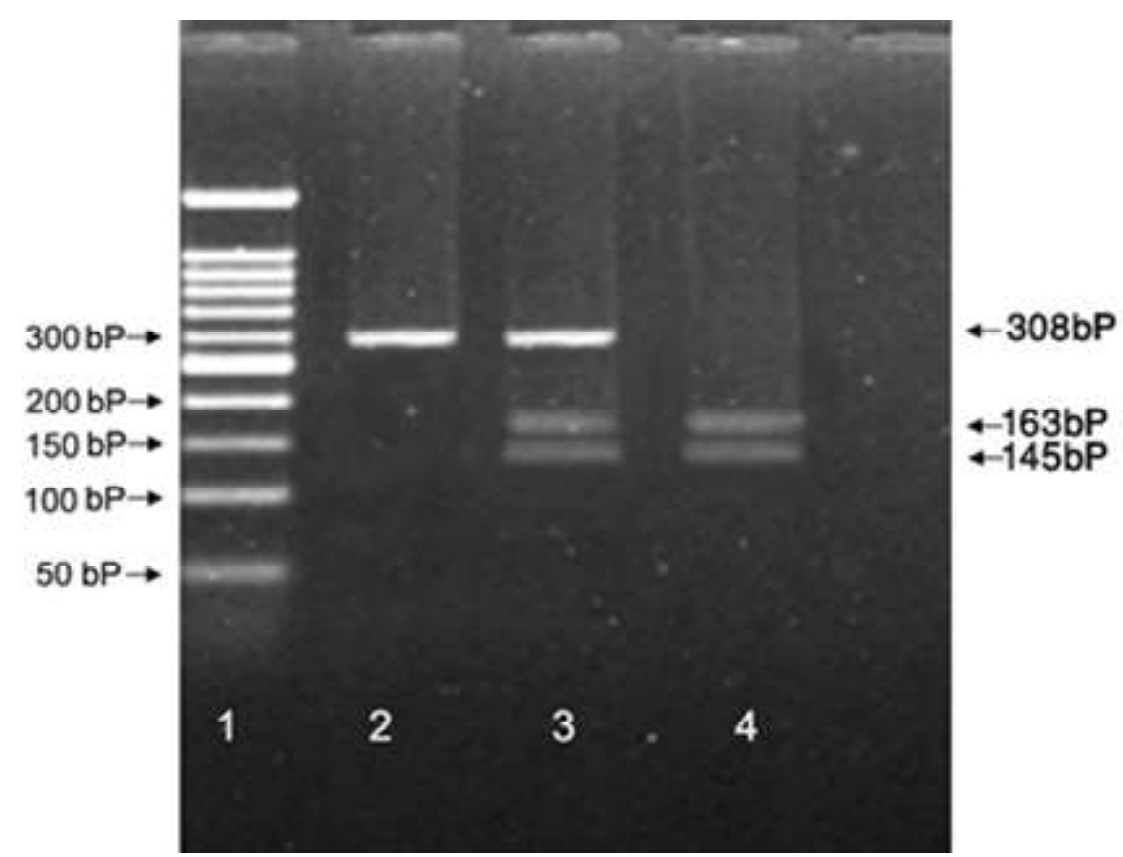

Figure 1. PCR-RFLP for WNT7A (rs104893832) polymorphism using BsrDI restriction enzyme digestion. Lane 1 shows 50 bp DNA markers on 3\% agarose gel electrophoresis. Lane 2 represents A/A genotype, lane 3 represents heterozygous $(\mathrm{A} / \mathrm{G})$ and lane 4 is $\mathrm{G} / \mathrm{G}$ genotype 
adult mice. Gilbert ${ }^{(20)}$ also indicated that the WNT7A gene is one of the most important genes that control fertilization, implantation and pregnancy. Based on the previously reported functions of the WNT7A gene, our results in this study show that there is a relation between the polymorphism of WNT7A gene and RSA. The findings in this research can be an indication that the Wnt7 gene plays a key role in RSA.

Therefore, the WNT7A (rs104893832) polymorphism may be a genetic risk factor for RSA in our population. With the increasing recognition of genetic-environmental interactions in the etiology of RSA, it is necessary to include genetic information into epidemiological studies to identify how some polymorphic traits are associated with several phenotypic traits. Therefore, the indicated association of the WNT7A (rs104893832) polymorphism may be population-specific and influenced by environmental factors. However, our knowledge about the genetic factors determining RSA in general population is still limited. And this association might be population specific and highly influenced by environmental factors. However further studies are necessary to confirm the association in other populations.

\section{CONCLUSION}

The results conclusively indicated that WNT7A (rs104893832) polymorphism increased the risk of RSA in our research subjects.

\section{CONFLICT OF INTEREST}

There is no conflict of interest in this report.

\section{ACKNOWLEDGMENT}

Special thanks are due to Tehran Women's General Hospital (Mirza Kochak Khan), and Medical Biotechnology Research Center of Ashkezar Branch for financial support.

\section{AUTHORS' CONTRIBUTIONS}

MM was responsible for writing of the article. MDA was responsible for submission of the article. SMS was the advisor. All authors have read and approved the final manuscript.

\section{REFERENCES}

1. Doubilet PM, Benson CB, Bourne T, et al. Diagnostic criteria for nonviable pregnancy early in the first trimester. N Engl J Med 2013;369:144351. doi: 10.1056/NEJMra1302417.

2. Larsen EC, Christiansen OB, Kolte AM, et al. New insights into mechanisms behind miscarriage. BMC Med 2013;11:154-9. doi: 10.1186/17417015. 11.154.

3. Kaur R, Gupta K. Endocrine dysfunction and recurrent spontaneous abortion: an overview. Int J Appl Basic Med Res 2016;6:79-83. doi: 10.4103/ 2229-516X.179024.

4. Nigro G, Mazzocco M, Mattia E, et al. Role of infections in recurrent spontaneous abortion. $\mathrm{J}$ Matern Fetal Neonatal Med 2011;24:983-89. doi: 10.3109/14767058.2010.547963.

5. Wong LF, Porter T, Scott JR. Immunotherapy for recurrent miscarriage. Cochrane Database of Systematic Reviews 2014;10:112-8. doi: 10.1002/ 14651858.CD000112.pub3.

6. Battinelli EM, Marshall A, Jean M. The role of thrombophilia in pregnancy. Thrombosis 2013;3:487-501. doi: 10.1155/2013/516420.

7. Lassi Z, Imam A, Dean SV, et al. Preconception care: caffeine, smoking, alcohol, drugs and other environmental chemical/radiation exposure. Reprod Health 2014;26:154-60. doi: 10.1186/ 1742475511.

8. Hyde KJ, Schust DJ. Genetic considerations in recurrent pregnancy loss. Cold Spring Harb Perspect Med 2015;5:a023119. doi: 10.1101/ cshperspect.a023119.

9. $\mathrm{He} \mathrm{H}, \mathrm{Li} \mathrm{T}$, Yin D, et al. HOXA10 expression is decreased by testosterone in luteinized granulosa cells in vitro. Mol Med Rep 2012;6:51-6. doi: 10.3892/mmr.2012.875.

10. Quinonez SC, Innis JW. Human HOX gene disorders. Mol Genet Metab 2014;111:4-15. doi: $10.1016 / 10012$.

11. May L, Kuningas M, Bodegom D, et al. Genetic variation in pentraxin (PTX) 3 gene associates with PTX3 production and fertility in women. Biol Reprod 2010;82:299-304. doi: 10.1095/biolreprod. 109.079111 . 
12. Tiwari M, Prasad S, Pandey NA, et al. Nitric oxide signaling during meiotic cell cycle regulation in mammalian oocytes. Front Biosci 2017;9:307-318. doi: $10.2741 / \mathrm{s} 489$.

13. Garavelli L, Wischmeijer A, Rosato S, et al. AlAwadi-Raas-Rothschild (limb/pelvis/uterushypoplasia/aplasia) syndrome and WNT7A mutations: genetic homogeneity and nosological delineation. Am J Med Genet 201 1;155:332-6. doi: 10.1002/ajmg.a.33793.

14. Sondereggera S, Pollheimerb J, Knoflerb M. Wnt Signalling in implantation, decidualisation and placental differentiation - review. Placenta 2010;31:839-47. doi: 10.1016/j.placenta.2010. 07.011 .

15. Vainio S, Heikkila M, Kispert A, et al. Female development in mammals is regulated by Wnt-4 signalling. Nature 1999;397:405-409.

16. Fan X, Krieg S, Hwang J, et al. Dynamic regulation of Wnt7a expression in the primate endometrium: Implications for postmenstrual regeneration and secretory transformation. Endocrinol 2012:153: 1063-1069. doi: 10.1210/en.2011-1826.
17. Tepekoy F, Akkoyunlu G, Demir R. The role of Wnt signaling members in the uterus and embryo during pre-implantation and implantation. J Assist Reprod Genet 2015;32:337-348 doi: 10.1007/s10815-014-0409-7.

18. Dunlap KA, Filant J, Hayashi K, et al. Postnatal deletion of Wnt7a inhibits uterine gland morphogenesis and compromises adult fertility in mice. Biol Reprod 2011;85:386-96. doi: 10.1095/ biolreprod.111.091769.

19. van Amerongen R, Nusse R. Towards an integrated view of Wnt signaling in development. Development 2009;136:3205-14. doi: 10.1242/ dev.033910.

20. Gilbert SF. Developmental biology. $9^{\text {th }}$ ed. Sunderland: Mass Sinauer Associates;2010. 